\title{
Renal Function after Coronary Artery Bypass Graft Using Dexmedetomidine
}

\author{
Alexandre Fabricio Martucci ${ }^{1}$, Yara Marcondes Machado Castiglia ${ }^{2}$ \\ ${ }^{1}$ Ponta Grossa State University, Ponta Grossa, Brazil; ${ }^{2}$ Botucatu College of Medicine, Botucatu, Brazil. \\ Email: afmartucci@gmail.com \\ Received September $18^{\text {th }}, 2013$; revised October $19^{\text {th }}, 2013$; accepted November $2^{\text {nd }}, 2013$ \\ Copyright (C) 2013 Alexandre Fabricio Martucci, Yara Marcondes Machado Castiglia. This is an open access article distributed under \\ the Creative Commons Attribution License, which permits unrestricted use, distribution, and reproduction in any medium, provided \\ the original work is properly cited.
}

\begin{abstract}
Acute kidney injury (AKI) is defined by $0.3 \mathrm{mg} / \mathrm{dL}$ increase in serum creatinine ( $\mathrm{SCr}$ ) and is associated with higher incidence of postoperative mortality after coronary artery bypass graft (CABG). There are few clinical studies on the effect of dexmedetomidine (DEX) on renal function. We evaluated AKI after coronary artery bypass graft with and without cardiopulmonary bypass (CPB) under anesthesia with DEX. Method: In this retrospective study, we performed serial analysis of serum creatinine (SCr) up to 48 hours after surgery in 286 patients who underwent CABG. We tested the similarity between groups, evaluating patients separately for use of CPB and DEX. Each patient was evaluated for his or her $\mathrm{SCr}$ at the following points in time: preoperative, immediately postoperative, 24 hours postoperative, and 48 hours postoperative. Preoperative SCr was used as the baseline value for each patient. If the $\mathrm{SCr}$ increased $\geq 0.3 \mathrm{mg} / \mathrm{dL}$ in at least one of the periods, the patient was classified as having AKI. We also assessed the risk for AKI in patients with altered preoperative $\mathrm{SCr}$ (values between 1.1 to $2.0 \mathrm{mg} / \mathrm{dL}$ for women or 1.3 to $2.0 \mathrm{mg} / \mathrm{dL}$ for men) compared to patients with normal SCr. Results: The groups were similar for preoperative weight, age, and altered SCr. Patients were anesthetized with DEX and who underwent CPB exhibited higher incidence of AKI $(p=0.043)$. Without CPB, there was higher incidence of AKI after using DEX $(p=0.066)$. Conclusion: Anaesthesia with DEX increased the incidence of AKI after myocardial revascularization surgery in patients who underwent CPB.
\end{abstract}

Keywords: Acute Kidney Injury; Dexmedetomidine; Cardiopulmonary Bypass; Coronary Artery Bypass Graft

\section{Introduction}

Acute kidney injury (AKI) $[1,2]$ is defined by $0.3 \mathrm{mg} / \mathrm{dl}$ increase in serum creatinine ( $\mathrm{SCr}$ ) and is associated with higher incidence of postoperative mortality after myocardial revascularization surgery [3-7]. As indicated by its pathophysiology, AKI has multifactorial causes, including low cardiac output, hypoperfusion, hypovolemia, diabetes mellitus, age $\geq 65$ years old, emergency surgery, renal ischemia, use of cardiopulmonary bypass (CPB), and adopted rewarming method after CPB [7-15]. There is $30 \%$ incidence of AKI in patients undergoing myocardial revascularization and approximately $1 \%$ will require dialysis $[7,8,16]$.

Dexmedetomidine (DEX) is an $\alpha_{2}$-adrenoceptor agonist with $\alpha_{2} / \alpha_{1}$ selectivity of 1600:1. Doses between 0.2 $0.6 \mu \mathrm{g} / \mathrm{kg} / \mathrm{h}$ promote sedation, anxiolysis, hypnosis, and analgesia with little or no change in breathing [17]. DEX acts on three types of $\alpha_{2}$ receptors (A, B, and C). The $\alpha_{2 \mathrm{~A}}$ has been described in the periphery and $\alpha_{2 \mathrm{~B}}$ and $\alpha_{2 \mathrm{C}}$ in the central nervous system (CNS). In the periphery, the presynaptic receptors inhibit noradrenaline release, while post-synaptic receptors determine vasoconstriction. DEX acts on central receptors, causing sympatholysis, sedation, and antinociception [18]. In the cardiovascular system, DEX reduces heart rate, peripheral vascular resistance, and indirectly, myocardial contractility, cardiac output, and systemic pressure. Incidences of bradycardia and hypotension have been associated with loading dose. Under anesthesia, DEX drastically reduces the minimum alveolar concentration (MAC) [19]. In cardiac surgery, DEX reduces catecholamine plasma concentrations, maintains hemodynamic stability, and increases urinary output [20]. Despite maintaining antidiuretic hormone (ADH) concentration, another $\alpha_{2}$ agonist, clonidine, increases diuresis and creatinine clearance on the first night after surgery [21]. Thus, with respect to renal function, 
DEX may be a promising agent for use in myocardial revascularization surgery. Therefore, we conducted a retrospective study to assess the effect of using DEX intraoperatively on postoperative renal function in patients who underwent myocardial revascularization surgery with and without $\mathrm{CPB}$.

\section{Methods}

This retrospective study was approved by the appropriate ethics authority (Ref: 120/2011) and registered with REBEC (Ref: U1111-1128-4201). Written informed consent was waived by the ethics committee. We selected patients who underwent anaesthesia for myocardial revascularization between January 2008 and December 2011. We excluded patients who met the following exclusion criteria: underwent emergency surgery and catheterization within less than 72 hours before the operation, had $\geq 2 \mathrm{mg} / \mathrm{dl}$ serum creatinine ( $\mathrm{SCr}$ ) before surgery, had incomplete data, and patients with continued use of $\alpha_{2}$ agonist. Patients were divided into the following groups based on use of CPB and DEX:

Group $\mathbf{G}_{(\mathrm{CPB})}-\mathrm{CPB}$ patients

Group $\mathbf{G}_{(\text {Control) }}$-non-CPB patients

Group $\mathbf{G}_{(\mathbf{C P B}+\mathbf{D E X})}-\mathrm{CPB}$ patients who received DEX

Group $\mathbf{G}_{(\mathrm{DEX})}$-non-CPB patients who received DEX

For $\mathbf{G}_{(\mathbf{C P B})}$ and $\mathbf{G}_{(\mathbf{C o n t r o l )}}$, the anesthesia protocol began with 3 to $5 \mathrm{mg}$ of intravenous midazolam. Standard ASA monitors were attached, and radial artery catheterization was used for monitoring mean arterial pressure. We injected 20 to $30 \mu \mathrm{g} / \mathrm{kg}$ fentanyl, $0.3 \mathrm{mg} / \mathrm{kg}$ etomidate, and $0.08 \mathrm{mg} / \mathrm{kg}$ pancuronium. Anaesthesia was maintained by isoflurane titration according to hemodynamic response using $60 \% \mathrm{O}_{2}$ as carrier. Mean arterial pressure was maintained between 60 and $90 \mathrm{mmHg}$. We used metaraminol or ephedrine for short episodes of hypotension, noradrenaline for episodes of low peripheral vascular resistance, dobutamine to increase cardiac inotropism, and sodium nitroprusside or nitroglycerin for hypertensive crisis.

For $\mathbf{G}_{(\mathbf{C P B}+\mathbf{D E X})}$ and $\mathbf{G}_{(\mathbf{D E X})}$, we used DEX at $0.5 \mu \mathrm{g} /$ $\mathrm{kg} / \mathrm{h}$ dose immediately after venipuncture and monitoring without loading dose, then reducing the fentanyl dose to 10 to $20 \mu \mathrm{g} / \mathrm{kg}$. Use of isoflurane and vasoactive agents was kept the same as for $\mathbf{G}_{(\mathbf{C P B})}$ and $\mathbf{G}_{(\mathbf{C o n t r o l )}}$.

To start CPB, the patients were anticoagulated with sodium heparin $(4 \mathrm{mg} / \mathrm{kg})$ or until reaching activated clotting time (ACT) higher than 480 seconds. During CPB, nonpulsatile flow was used with target mean arterial pressure from 50 to $80 \mathrm{mmHg}$. Temperature was measured with a nasopharyngeal thermometer and maintained between $30^{\circ} \mathrm{C}$ and $35^{\circ} \mathrm{C}$ during CPB.

To quantify AKI rates in patients who underwent $\mathrm{CABG}$ with and without $\mathrm{CPB}$, we used the results from tests routinely performed at the following time points: preoperative $\left(\mathrm{M}_{\text {pre }}\right)$, immediately postoperative $\left(\mathrm{M}_{\mathrm{iPO}}\right), 24$ hours postoperative $\left(\mathrm{M}_{\mathrm{PO} 24}\right)$, and 48 hours postoperative $\left(\mathrm{M}_{\mathrm{PO48}}\right)$. These data were collected by reviewing electronic records available in the TASY ${ }^{\circledR}$ program, version 2.6, developed and licensed by Whebsistemas. The following were used as criteria to define AKI: AKIN (Acute Kidney Injury Network), $\geq 0.3 \mathrm{mg} / \mathrm{dl}$ increase in $\mathrm{SCr}$ concentration, or $\geq 50 \%$ increase in $\mathrm{SCr}$ concentration from baseline within at least 48 hours without urine output analysis [1]. Each patient was evaluated for $\mathrm{SCr}$ concentration at time points starting from $\mathrm{M}_{\text {pre }}$. The $\mathrm{SCr}$ concentration at each time point was compared to that in $\mathrm{M}_{\text {pre }}$. If at least one of these comparisons between time points indicated $\geq 0.3 \mathrm{mg} / \mathrm{dl}$ increase in $\mathrm{SCr}$ concentration, the patient was classified as having AKI. We also assessed risk for AKI in patients with altered preoperative $\mathrm{SCr}$ (values between $1.1 \mathrm{mg} / \mathrm{dl}$ and $2.0 \mathrm{mg} / \mathrm{dl}$ for women or $1.3 \mathrm{mg} / \mathrm{dl}$ and $2.0 \mathrm{mg} / \mathrm{dl}$ for men) compared to patients with normal SCr.

The statistical analysis aimed to test whether there was significant difference in incidence of AKI when using DEX, thus we separated patients who underwent CPB from those who did not. We considered Student t-test for independent samples in comparing two groups with respect to quantitative variables. We considered Fisher exact and Chi-square tests in assessing the association between qualitative variables. Values were considered statistically significant at $\mathrm{p}<0.05$.

\section{Results}

We evaluated 543 patients, of whom 257 patients were excluded because they met the exclusion criteria. A total of 286 patients were included in the statistical study, distributed as follows: $\mathrm{G}_{\mathrm{CPB}}, 157$ patients; $\mathrm{G}_{\mathrm{CPB}}+\mathrm{DEX}, 50$ patients; $\mathrm{G}_{\text {control }}, 55$ patients; and $\mathrm{G}_{\mathrm{DEX}}, 24$ patients.

We confirmed similarity between groups for weight, age, preoperative $\mathrm{SCr}$, and incidences of hypertension (HTN) and diabetes mellitus (DM) preoperatively, for samples with and without CPB (see Tables 1 and 2).

Analysis of the results tested if there was some other factor associated with the AKI studied. Among the groups that underwent $\mathrm{CPB}$ or not, we separately tested weight, age, and altered preoperative $\mathrm{SCr}$ concentration up to $2 \mathrm{mg} / \mathrm{dl}$. For those patients who did not undergo CPB and received DEX or not, only age $(p=0.008)$, but not weight $(\mathrm{p}=0.912)$ or altered $\mathrm{SCr}(\mathrm{p}=0.488)$, was associated with higher incidence of AKI. Incidence of AKI was higher in the group that received DEX, even in patients who did not undergo $\mathrm{CPB}$, but without statistical significance $(p=0.066)$ (Figure 1).

For groups that underwent CPB, the DEX factor was associated with a higher incidence of AKI ( $p=0.043$; beta error of 0.273) (Figure 2). In these patients, age ( $p=$ $0.224)$, weight ( $\mathrm{p}=0.067)$, and altered SCr up to $2 \mathrm{mg} / \mathrm{dl}$ 
Table 1. Testing similarity of the groups that were submitted to CPB and that received or did not receive DEX, for weight, age, and altered preoperative serum creatinine concentration up to $2 \mathrm{mg} / \mathrm{dl}$.

\begin{tabular}{|c|c|c|c|c|c|c|c|c|}
\hline Variable & DEX & $\mathrm{n}$ & Mean & Median & Minimum & Maximum & Standard deviation & p-value ${ }^{*}$ \\
\hline \multirow{2}{*}{ Age } & Without & 157 & 64.0 & 64.0 & 36.0 & 87.0 & 9.0 & \multirow{2}{*}{0.755} \\
\hline & With & 50 & 64.4 & 65.0 & 39.0 & 82.0 & 9.8 & \\
\hline \multirow{2}{*}{ Weight } & Without & 157 & 74.7 & 73.0 & 45.0 & 116.0 & 13.4 & \multirow{2}{*}{0.347} \\
\hline & With & 50 & 72.8 & 72.5 & 44.0 & 97.0 & 11.7 & \\
\hline \multirow{2}{*}{$\begin{array}{l}\text { Altered Pre-Op. } \\
\text { Creatinine }\end{array}$} & Without & 157 & 1.20 & 1.18 & 0.63 & 1.98 & 0.28 & \multirow{2}{*}{0.171} \\
\hline & With & 50 & 1.14 & 1.15 & 0.72 & 1.60 & 0.24 & \\
\hline
\end{tabular}

*Student t-test for independent samples.

Table 2. Testing similarity of the groups that were not submitted to CPB and that received or did not receive DEX, for weight, age, and altered preoperative serum creatinine concentration up to $2 \mathrm{mg} / \mathrm{dl}$.

\begin{tabular}{|c|c|c|c|c|c|c|c|c|}
\hline Variable & DEX & $\mathrm{n}$ & Mean & Median & Minimum & Maximum & Standard deviation & p-value* \\
\hline \multirow{2}{*}{ Age } & No & 55 & 61.8 & 65.0 & 34.0 & 85.0 & 11.9 & \multirow{2}{*}{0.097} \\
\hline & Yes & 24 & 65.5 & 67.0 & 48.0 & 78.0 & 7.2 & \\
\hline \multirow{2}{*}{ Weight } & No & 55 & 73.8 & 73.0 & 47.0 & 119.0 & 13.8 & \multirow{2}{*}{0.862} \\
\hline & Yes & 24 & 73.2 & 72.5 & 40.0 & 101.0 & 15.7 & \\
\hline \multirow{2}{*}{$\begin{array}{l}\text { Alt. Pre-Op. } \\
\text { Creatinine }\end{array}$} & No & 55 & 1.11 & 1.10 & 0.68 & 1.92 & 0.28 & \multirow{2}{*}{0.649} \\
\hline & Yes & 24 & 1.08 & 1.13 & 0.71 & 1.44 & 0.23 & \\
\hline
\end{tabular}

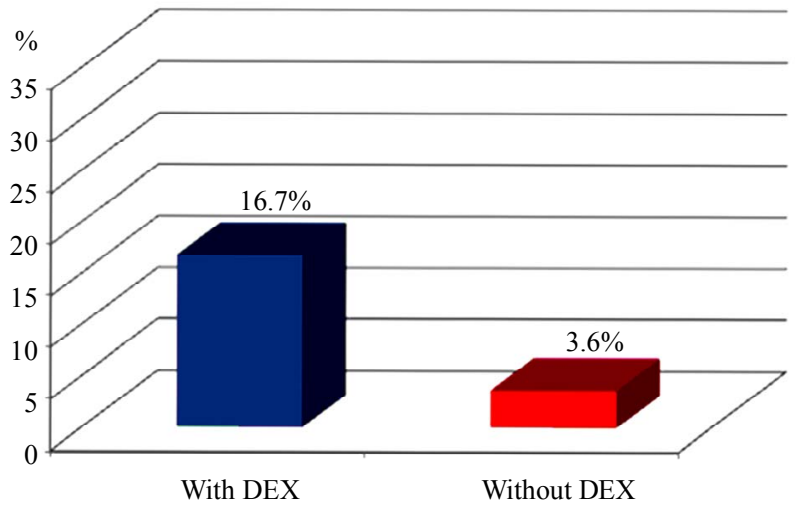

Figure 1. Percentage of cases with acute kidney injury (AKI) according to DEX use in patients who were not submitted CPB ( $=0.066$; beta error of 0.831$)$.

$(\mathrm{p}=0.364)$ exhibited no statistically significant association with AKI.

\section{Discussion}

In this study, we found higher incidence of AKI in groups that received DEX regardless of CPB use. We also observed similarity for preoperative creatinine, sex, age, weight, and incidence of HTN and DM in the sample studied, further validating the results of this retrospective study. The age factor was associated with in-

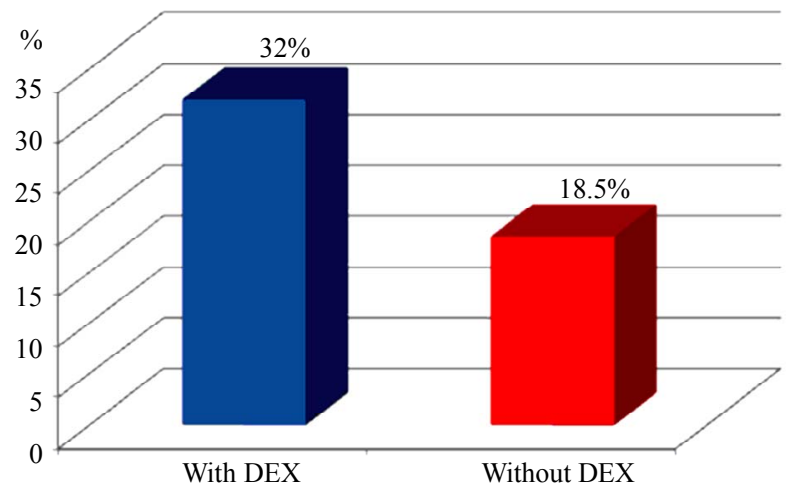

Figure 2. Percentage of acute kidney injury cases in patients who were submitted to CPB according to DEX use (p = 0.043; beta error of 0.273 ).

creased incidence of AKI in the non-CPB group, as expected for changes associated with aging [13,22]. Although, age is not necessarily a risk factor, other studies corroborate the results found for the non-CPB group [3-7].

$\mathrm{SCr}$ is a late biomarker of AKI. Although other biomarkers, such as KIM-1 (Kidney Injury Molecule), NAG (N-acetyl-B-D-glucosaminidase), NGAL (Neutrophil Gelatinase Associated Lipocalin), IL-18 (Interleukin 18), or cystatin $\mathrm{C}$ seem promising, the present definition of AKI is still based on altered serum creatinine concentration 
and urine output [23-25]. Urinary output can increase the sensitivity for diagnosing AKI, but as this parameter is used to determine the phase of AKI, very constant measurements are required, which poses considerable difficulty in clinical practice [26]. Current clinical practices do not emphasize small SCr increases, which are often attributed to laboratory variation. However, the coefficient of variation of $\mathrm{SCr}$ with modern analyzers is relatively small and therefore $0.3 \mathrm{mg} / \mathrm{dL}$ increases are unlikely to be caused by laboratory variation [27]. According to Tolpin and colleagues [5], even subclinical increases are associated with worse prognosis. However, there is an overall consensus that diagnostic criteria should only be applied when optimal hydration status has been established [1].

$\mathrm{CPB}$ is an AKI-independent risk factor in renal function after myocardial revascularization surgery. The causes contributing to $\mathrm{CPB}$ as a risk factor are still being studied, but several factors have been proposed, such as hypothermia and rewarming, oxygen delivery to the kidneys (renal $\mathrm{DO}_{2}$ ), perfusion method employed, perfusion pressure, and CPB duration itself $[4,6,10,14,15,28,29]$. Each factor would partially contribute to some kind of injury. Because the $\mathrm{SCr}$ values obtained before surgery are similar enough among all patients studied, this could emphasize intraoperative factors as probable determinants of AKI, including use of CPB and DEX.

Kulka and colleagues [21] studied preoperative treatment of patients undergoing myocardial revascularization with clonidine ( $4 \mu \mathrm{g} / \mathrm{kg}$ intravenously) and believe that this other agonist $\alpha_{2}$ prevented renal function deterioration in patients, probably by reducing the sympathetic nervous system response. These authors' conclusion was based on studying creatinine clearance in patients treated with agonist $\alpha_{2}$ compared to creatinine clearance in untreated patients. At three days after surgery, the clearances of the two groups were equal. However results from additional clinical trials are still necessary.

An in vitro experiment with human kidney cells and in vivo experiment with mice demonstrated that DEX activates the cell survival signal, phosphorylated AKT antibody (pAKT) via $\alpha_{2}$ adrenoceptors, to reduce cell death and release the nuclear protein HMGB1 (high mobilitygroup box-1) in the plasma, inhibiting TLR4 (toll-like receptor 4) signaling, where both HMGB1 and TLR4 determine renal protection and play a central role in coordinating inflammatory responses in renal ischemia and reperfusion. DEX also has protective properties for organs as well as cytoprotective and anti-inflammatory effects, protecting against renal injury after ischemia and reperfusion. The authors of the study believe that, if extrapolated to clinical practice, their results indicate that DEX determines renal protection against ischemia and reperfusion injuries [30].
In contrast, other authors of histological studies found that using DEX in rats caused dilation, degeneration, and necrosis of renal tubules after hemorrhage of $30 \%$ of volemia, without replacing this loss. However, there was reduced renal vascular resistance in organ function, with increased glomerular filtration and renal filtration fraction [31].

In this retrospective study it was not possible to obtain a precise conclusion due to the sample size. Missing data, emergency surgeries, and other exclusion criteria left us with a small sample, especially for the non-CPB group. However, we found that DEX increased the incidence of AKI in the CPB group. In patients without CPB use, DEX was not considered an independent risk factor for AKI because $p$-value was 0.066 , which would only indicate a statistically significant trend with a larger sample power. Thus, more patients are probably necessary to demonstrate if DEX is also a risk factor for AKI in patients not undergoing $\mathrm{CPB}$.

\section{Conclusion}

In conclusion, albeit with a small sample, we observed that DEX behaved as an independent risk factor for increased incidence of AKI after CABG in patients who used CPB. For the non-CPB group, our sample was too limited to reach a conclusion.

\section{Acknowledgements}

Mr. Ary Elias Sabbag Jr., for his help with statistical analysis.

\section{REFERENCES}

[1] R. L. Mehta, J. A. Kellum, S. V. Shah, B. A. Molitoris, C. Ronco, D. G. Warnock and A. Levin, "Acute Kidney Injury Network: Report of an Initiative to Improve Outcomes in Acute Kidney Injury," Critical Care, Vol. 11, No. 2, 2007, p. R31. http://dx.doi.org/10.1186/cc5713

[2] "American Society of Nephrology Renal Research Report," Journal of the American Society of Nephrology, Vol. 16, No. 7, 2005, pp.1886-1903. http://dx.doi.org/10.1681/ASN.2005030285

[3] I. Bahar, A. Akgul, M. A. Ozatik, K. M. Vural, A. E. Demirbag, M. Boran and O. Tasdemir, "Acute Renal Failure Following Open Heart Surgery: Risk Factors and Prognosis," Perfusion, Vol. 20, No. 6, 2005, pp. 317-322. http://dx.doi.org/10.1191/0267659105pf829oa

[4] G. M. Chertow, E. Burdick, M. Honour, J. V. Bonventre and D. W. Bates, "Acute Kidney Injury, Mortality, Length of Stay, and Costs in Hospitalized Patients," Journal of the American Society of Nephrology, Vol. 16, No. 11, 2005, pp. 3365-3370. http://dx.doi.org/10.1681/ASN.2004090740

[5] D. A. Tolpin, C. D. Collard, V. V. Lee, S. S. Virani, P. M. Allison, M. A. Elayda and W. Pan, "Subclinical Changes 
in Serum Creatinine and Mortality after Coronary Artery Bypass Grafting," The Journal of Thoracic and Cardiovascular Surgery, Vol. 143, No. 3, 2012, pp. 682-688. http://dx.doi.org/10.1016/j.jtcvs.2011.09.044

[6] A. B. Kumar and M. Suneja, "Cardiopulmonary BypassAssociated Acute Kidney Injury," Anesthesiology, Vol. 114, No. 4, 2011, pp. 964-970. http://dx.doi.org/10.1097/ALN.0b013e318210f86a

[7] D. J. Brito, V. J. Nina, R. V. Nina, J. A. Figueiredo Neto, M. I. Oliveira, J. V. Salgado, J. S. Lages and N. Salgado Filho, "Prevalence and Risk Factors for Acute Renal Failure in the Postoperative of Coronary Artery Bypass Grafting," The Revista Brasileira de Cirurgia Cardiovascular, Vol. 24, No. 3, 2009, pp. 297-304. http://dx.doi.org/10.1590/S0102-76382009000400007

[8] M. H. Rosner and M. D. Okusa, "Acute Kidney Injury Associated with Cardiac Surgery," Clinical Journal of the American Society of Nephrology, Vol. 1, No. 1, 2006, pp. 19-32. http://dx.doi.org/10.2215/CJN.00240605

[9] R. Ascione, G. Nason, S. Al-Ruzzeh, C. Ko, F. Ciulli and G. D. Angelini, "Coronary Revascularization with or without Cardiopulmonary Bypass in Patients with Preoperative Nondialysis-Dependent Renal Insufficiency," The Annals of Thoracic Surgery, Vol. 72, No. 6, 2001, pp. 2020-2025.

http://dx.doi.org/10.1016/S0003-4975(01)03250-7

[10] G. Asimakopoulos, A. P. Karagounis, O. Valencia, N. Alexander, M. Howlader, M. A. Sarsam and V. Chandrasekaran, "Renal Function after Cardiac Surgery offVersus On-Pump Coronary Artery Bypass: Analysis Using the Cockroft-Gault Formula for Estimating Creatinine Clearance," The Annals of Thoracic Surgery, Vol. 79, No. 6, 2005, pp. 2024-2031.

http://dx.doi.org/10.1016/j.athoracsur.2004.12.020

[11] J. W. Sear, "Kidney Dysfunction in the Postoperative Period," British Journal of Anaesthesia, Vol. 95, No. 1, 2005, pp. 20-32. http://dx.doi.org/10.1093/bja/aei018

[12] F. O. Santos, M. A. Silveira, R. B. Maia, M. D. Monteiro and R. Martinelli, "Acute Renal Failure after Coronary Artery Bypass Surgery with Extracorporeal CirculationIncidence, Risk Factors, and Mortality," Arquivos Brasileiros de Cardiologia, Vol. 83, No. 2, 2004, pp. 150$154 ; 145-159$.

[13] A. C. Kochi, A. S. Martins, M. C. Lima, L. C. Martin and A. L. Balbi, "[Preoperative Factors for the Development of Acute Kidney Injury after Cardiac Surgery: Prospective study]," Revista da Associação Médica Brasileira, Vol. 54, No. 3, 2008, pp. 208-213.

[14] M. Boodhwani, F. D. Rubens, D. Wozny and H. J. Nathan, "Effects of Mild Hypothermia and Rewarming on Renal Function after Coronary Artery Bypass Grafting," The Annals of Thoracic Surgery, Vol. 87, No. 2, 2009, pp. 489-495.

http://dx.doi.org/10.1016/j.athoracsur.2008.10.078

[15] A. Kourliouros, O. Valencia, S. D. Phillips, P. O. Collinson, J. P. van Besouw and M. Jahangiri, "Low Cardiopulmonary Bypass Perfusion Temperatures Are Associated with Acute Kidney Injury Following Coronary Artery Bypass Surgery," European Journal Cardio-Thoracic Surgery, Vol. 37, No. 3, 2010, pp. 704-709. http://dx.doi.org/10.1016/j.ejcts.2009.08.020

[16] M. D. Okusa, "The Inflamatory Cascade in Acute Ischemic Renal Failure," Nepron, Vol. 90, No. 2, 2002, pp. 133-138. http://dx.doi.org/10.1159/000049032

[17] J. E. Hall, T. D. Uhrich, J. A. Barney, S. R. Arain and T. J. Ebert, "Sedative, Amnestic, and Analgesic Properties of Small-Dose Dexmedetomidine Infusions," Anesthesia \& Analgesia, Vol. 90, No. 3, 2000, pp. 699-705. http://dx.doi.org/10.1097/00000539-200003000-00035

[18] V. Malhotra, V. Sudheendra, J. O'Hara and S. Diwan, "Anesthesia and the Renal and Genitourinary Systems." In: R. D. Miller, Ed., Miller's Anesthesia, Churchill Livingstone Elsevier, Philadelphia, 2009. pp. 2105-2134.

[19] J. G. Reves, P. S. A. Glass, D. A. Lubarsky, M. D. McEvoy and R. Martinez-Ruiz, "Intravenous Anesthetics,” In: R. D. Miller, Ed., Miller's Anesthesia, Churchill Livingstone Elsevier, Philadelphia, 2009. pp. 719-768.

[20] J. Jalonen, M. Hynynen, A. Kuitunen, H. Heikkila, J. Perttila, M. Salmenpera, M. Valtonen, R. Aantaa and A. Kallio, "Dexmedetomidine as an Anesthetic Adjunct in Coronary Artery Bypass Grafting," Anesthesiology, Vol. 86, No. 2, 1997, pp. 331-345. http://dx.doi.org/10.1097/00000542-199702000-00009

[21] P. J. Kulka, M. Tryba and M. Zenz, "Preoperative Alpha2-Adrenergic Receptor Agonists Prevent the Deterioration of Renal Function after Cardiac Surgery: Results of a Randomized, Controlled Trial," Critical Care Medicine, Vol. 24, No. 6, 1996, pp. 947-952.

http://dx.doi.org/10.1097/00003246-199606000-00012

[22] R. D. Lindeman and R. Goldman, "Anatomic and Physiologic age Changes in the Kidney," Experimental Gerontology, Vol. 21, No. 4-5, 1986, pp. 379-406. http://dx.doi.org/10.1016/0531-5565(86)90044-6

[23] M. Bennett, C. L. Dent, Q. Ma, S. Dastrala, F. Grenier, R. Workman, H. Syed, S. Ali, J. Barasch and P. Devarajan, "Urine NGAL Predicts Severity of Acute Kidney Injury after Cardiac Surgery: A Prospective Study," Clinical Journal of the American Society of Nephrology, Vol. 3, No. 3, 2008, pp. 665-673. http://dx.doi.org/10.2215/CJN.04010907

[24] M. L. Felicio, R. R. Andrade, Y. M. Castiglia, M. A. Silva, P. T. Vianna and A. S. Martins, "Cystatin C and Glomerular Filtration Rate in the Cardiac Surgery with Cardiopulmonary Bypass," The Revista Brasileira de Cirurgia Cardiovascular, Vol. 24, No. 3, 2009, pp. 305311.

http://dx.doi.org/10.1590/S0102-76382009000400008

[25] W. K. Han, G. Wagener, Y. Zhu, S. Wang and H. T. Lee, "Urinary biomarkers in the early detection of acute kidney injury after cardiac surgery," Clinical Journal of the American Society of Nephrology, Vol. 4, No. 5, 2009, pp. 873-882. http://dx.doi.org/10.2215/CJN.04810908

[26] S. S. Han, K. J. Kang, S. J. Kwon, et al. "Additional Role of Urine Output Criterion in Defining Acute Kidney Injury," Nephrology Dialysis Transplantation, Vol. 27, No. 1, 2012 pp. 161-165. http://dx.doi.org/10.1093/ndt/gfr312

[27] R. D. Perrone, N. E. Madias and A. S. Levey, "Serum Creatinine as an Index of Renal Function: New Insights 
into Old Concepts," Clinical Chemistry, Vol. 38, No. 10, 1992, pp. 1933-1953.

[28] M. I. Stallwood, A. D. Grayson, K. Mills and N. D. Scawn, "Acute Renal Failure in Coronary Artery Bypass Surgery: Independent Effect of Cardiopulmonary Bypass," The Annals of Thoracic Surgery, Vol. 77, No. 3, 2004, pp. 968-972. http://dx.doi.org/10.1016/j.athoracsur.2003.09.063

[29] F. de Somer, J. W. Mulholland, M. R. Bryan, T. Aloisio, G. J. Van Nooten and M. Ranucci, " $\mathrm{O}_{2}$ delivery and $\mathrm{CO}_{2}$ Production during Cardiopulmonary Bypass as Determinants of Acute Kidney Injury: Time for a Goal-Directed Perfusion Management?" Critical Care, Vol. 15, No. 4, 2011, p. R192. http://dx.doi.org/10.1186/cc10349

[30] J. Gu, P. Sun, H. Zhao, H. R. Watts, R. D. Sanders, N. Terrando, P. Xia, M. Maze and D. Ma, "Dexmedetomidine Provides Renoprotection against Ischemia-Reperfusion Injury in Mice," Critical Care, Vol. 15, No. 3, 2011 , p. R153. http://dx.doi.org/10.1186/cc10283

[31] M. A. Marangoni, A. Hausch, P. T. Vianna, J. R. Braz, R. M. Viero and Y. M. Castiglia, "Renal Function and Histology after Acute Hemorrhage in Rats under Dexmedetomidine Action," Acta Cirurgica Brasileira, Vol. 22, No. 4, 2007, pp. 291-298. http://dx.doi.org/10.1590/S0102-86502007000400011 